\title{
Study on Commissioning and Operating Scheme of Plasma Ignition System for Supercritical Units of Thermal Power Plant
}

\author{
Ruopu Yang \\ (School of Electrical and Electronic Engineering, North China Electric Power University,Baoding \\ 071003,China)
}

Keywords: supercritical, plasma ignition system, commissioning and operating scheme, outage scheme

\begin{abstract}
For the common existing problems of plasma ignition system of coal-fired boiler like burner coking, cathode heads working shortly and etc., the paper introduces the commissioning and operating scheme for the plasma ignition system of supercritical coal-fired boiler in detail, which would be used for reference to the similar problems.
\end{abstract}

\section{Introduction}

Plasma ignition technology makes good energy saving effect when starting and stopping running the coal-fired boiler and burning steadily at low load. The plasma ignition rechnology has already been applied to coal-fired boilers,especially boilers burning various soft coal and high-quality meagre coal. ${ }^{[1-5]}$ However, cathode heads change frequently due to the plasma burner burning out,burner cokes, arc breaks,or cathode heads workes shortly during the operation process of plasma ignition system (hereinafter referred to as ignition system),especially during the ignition commissioning stage. ${ }^{[3-6]}$ There are various reasons for the problems during start-up and operation process of ignition system. But it always debugs subsystems of ignition system respectively in many power plants. The integral commissioning of ignition system and whole unit has not been fully considered.

Therefore, it is necessary to debug the ignition system well.The complete commissioning and operation scheme of ignition system will ensure it runs smoothly. The paper takes the 600MW supercritical coal-fired boiler as an example, introducing subsystems commissioning scheme and ignition system commissioning scheme during boiler start-up process successively. As a result, a complete set of commissioning scheme for plasma ignition system has been formed to provide references for avoiding or reducing the operating problems of ignition system. It also provides good references for units of same kind.

\section{Technical Specification of Equipment System and Plasma System}

\subsection{Overview of Equipment System}

The 600MW supercritical coal-fired generator unit with DG-1910/25.4- II supercritical parameter boiler, critical direct-through boiler, single reheat, single furnace, double-pass tail, adjusting reheating steam temperature with flue gas damper and dry ash extraction. The design coal is Huainan soft coal. The check coal is mixed coal. Medium speed coal mill pressurized direct cold primary air fan pulverizing coal system is adopted. There are six medium speed coal mills for each boiler, five operating and one standby.

Fuel system is not set for the boiler. There are total eight plasma start-up burners at two layers. Each four start-up burners are arranged at one layer, corresponding to the bottom Lay A and Lay B burners respectively. There are two booster pumps for the ignition system, one for operating and the other one for standby. The lowest stable firing load without oil of plasma ignition device is 35\%BMCR.

\subsection{Composition and Technical Specification of the Plasma Ignition System}

The ignition system is composed of plasma ignition equipment and auxiliary system. The plasma ignition equipment is composed of plasma generator, plasma burner, power control cabinet, 
isolation transformer and etc. The auxiliary system is composed of carrier air system, cooling water system, thermal control system, image flame detecting system, cold furnace coal pulverizing system, primary air on-line monitoring system, plasma burner wall temperature monitoring device and etc.

As air demands for the plasma carrier of plasma generator are stable, dry and clean, adopt instrument compressed air system as carrier wind system. When the plasma generator stops working, shift automatically and provide sweeping wind by by-pass valve. Compressed air system is adopted for sweeping wind and carrier wind. When the plasma put into operation, the compressed air consumption of single plasma generator is $100 \mathrm{Nm}^{3} / \mathrm{h}$. When the plasma stops working and just sweeps, the compressed air consumption of single plasma generator is $50 \mathrm{Nm}^{3} / \mathrm{h}$

Install primary air heating equipment in the relevant coal pulverizing system. Install the air heater in the primary warm air pipeline at inlet of coal mill. When the boiler starts from cold, warm the inlet of coal mill with air heater.

The steam used for steam heater is derived from auxiliary steam system. The steam consumption of single coal mill is $6 \mathrm{t} / \mathrm{h}$. The system drain water is led to boiler starting drain water expander.

In order to monitor the flame of plasma ignition burner and for the convenience of combustion adjustment, install one set of image fire detection device for each plasma ignition burner. Install one image flame detecting probe on the peephole at the rear face of burner. Furthermore, the probe drivepipe extends to the front face of burner along the secondary air chamber. CCD probe is installed inside the front of probe drivepipe, which corresponds to eight video signals of eight plasma ignition burners transmitting to industrial television system.

Two layers of plasma ignition burners and flame detecting cooling air system of other four layers of pulverized coal burners are merged. The cooling air parameters of image flame detecting system are $50 \mathrm{~m}^{3} / \mathrm{h}$ for single burner, $8 \times 50=400 \mathrm{~m}^{3} / \mathrm{h}$ for the whole boiler. The wind pressure is not less than $2500 \mathrm{~Pa}$.

Main parameters of plasma ignition system are as follows: The available regulating range of plasma generator is $80-120 \mathrm{~kW}$. The service life of replaceable cathode (operation hours) is not less than $400 \mathrm{~h}$. The service life of replaceable anode is not less than $1000 \mathrm{~h}$. The designed rated output range is $4-10 \mathrm{t} / \mathrm{h}$ when the plasma of single burner works. The stable ignition time is not longer than 120 s when starting from cold. The service time of burner is not less than 50000h.

\section{Commissioning Scheme of 600MW Plasma Ignition Subsystems}

\subsection{Commissioning Objectives}

Debug the plasma burner and system part by part in order to eliminate the existing and possible defects, hidden dangers and sundries and satisfy requirements to the normal washpipe operation and startup of 600MW unit. Specific requirements of plasma ignition system are as follows:

(1) Every performance index meets design requirements of manufacturers.

(2) The program control system of the ignition system shall meet operating requirements of the whole unit.

(3) Every meter of the ignition system is put into use normally. Operating station and local instruction are correct.

(4) Two sets of plasma ignition system can be ignited alone.

\subsection{Commissioning Contents and Procedure}

\subsubsection{Commissioning Cooling Water System of Plasma Burner}

(1) Check whether the position of every valve of cooling water system meets requirements. Close all water drain valves.

(2) Check and make sure that the closed water system of boiler has put into use.

(3) The interlock test on cooling water booster pump of plasma burner has already been finished.

(4) Check and make sure that the insulation of cooling air booster pump of plasma burner is qualified at the remote-control position and well powered. 
(5) Check and make sure that the sound and vibration of water pump and motor are normal after starting cooling booster pump. Check whether the system leaks or not.Make sure that water flows out from all return water pipes. Guarantee that the cooling water pressure meets single requirements.

\subsubsection{Commissioning Carrier Air of Plasma Burner and Image Fire Detecting Cooling Air System}

(1) Check the appearance of equipment, pipeline, valves and pressure gauges of carrier air system. Make sure that all of them are well connected.

(2) Take in air in the header of carrier air system. Open the hand valves, manual ball valves and electric ball valves of plasma generator. Blow and purge every branch. (Do not connect the plasma generator with hosepipe. ) Connect plasma generator after purging. Then open the manual inlet valve of header of carrier air system. Check and make sure that all pressure gauges of the system indicate correctly. Moreover, check and ensure zero leakage at the junction of all valves and flanges.

(3) Recheck every pressure switch by adjusting pressure in order to ensure it works correctly and sensitively. Adjust the preesure of carrier air within the normal working range.

(4) Check the cooling air system and ensure there is no installation defects of valves, probes, hanger frames and pipeline.

(5) Check the image fire detecting probes and ensure that the installation position and angle are correct.

(6) Start fire detecting cooling fan and purge the system. Dismantle the components inside of probes.

\subsubsection{Commissioning Image Fire Detecting System of Plasma Burner}

(1) Check the local control cabinet of draught fan, multipicture separator, video table, wiring of industrial television and ensure that all of them are well connected.

(2) Check whether the industrial television and multipicture separator are powered from central control room.

(3) Adjust the viewpoint of flame detecting probes at the initial stage of boiler ignition. Make sure that the viewpoint of all probes are consistent.

\subsubsection{Transmission Test on Interlocks and Protections of Plasma Ignition System}

Combined with design and control characteristics, it is necessary to modify testing contents of interlocks and protections and finish all related tests before ignition while ensuring the unit safety and normal operation of ignition system.

\subsubsection{Cold Arc Test of Plasma Ignition System}

(1) Check the connector wire of the following equipment and ensure correctness, such as power cabinet, isolating transformer, central control room PLC, plasma igniter and etc.

(2) Pressure test and insulation test of the following equipment shall be carried out: isolation transformer, cable and etc. Make sure that all of them meet requirements.

(3) After finishing the above commissioning tests, power on the power cabinet. Switch on the control power supply and fan power supply after power on. Check and make sure that the rotary direction of fan is right.

(4) Check and make sure that the communication status of central control room and power cabinet is right.

(5) Check the local position of plasma igniter and make sure that the cooling water and carrier air piping are connected correctly.

(6) Make sure that there is no leakage of cooling water pipelines which will work well. Adjust the pressure of cooling water.

(7) Make sure that there is no leakage of carrier air pipelines which will work well. Adjust the pressure of carrier air.

(8) Remote-control and operate every plasma igniter separately. Make sure that all of them can put into use well. 
(9) After finish the single arc test, put into "plasma model”. Program-controlled arc test shall be carried out in accordance with the procedure.

\subsubsection{Commissioning Air Heater System}

The heating steam of air heater of plasma ignition system derives from auxiliary steam header with parameters of $1.2 \mathrm{Mpa}$ and $350^{\circ} \mathrm{C}$. The inlet wind temperature of air heater is about $20^{\circ} \mathrm{C}$. The outlet wind temperature is $160^{\circ} \mathrm{C}$. The outlet wind temperature of coal mill is controlled within the range of $65^{\circ} \mathrm{C} \sim 82^{\circ} \mathrm{C}$.

(1) Check whether the primary air system is completely and correctly installed or not. Make sure that the front and back air flue of air heater, air heater, steam inlet and drain pipelines, burner, valves and wind boxes are installed well.

(2) Check the air heater and ensure that valves and traps on the steam inlet pipelines are adjusted flexibly. All of the valves indicate correctly, switch fully.

(3) At the initial stage of using air heater, drain water through trap bypass after ensuring that the water quality reaches the standards.

(4) When the air heater put into use, it is necessary to warm pipes step by step. Check and make sure that the steam and drainage system are tight without leakage.

(5) When the primary air system is qualified to ventilate, recheck and make sure the front and back air flue of air heater, systems around burner and wind boxes are tight without leakage.

(6) Open the air heater, grind the coal mill warmly. Adjust the ventilation quantity of the coal mill constantly and record the wind pressure and temperature at the inlet and outlet of air heater. Test the performance of air heater.

\subsubsection{Commissioning Plasma Ignition System in Hot State}

(1) Check the baffle angle of outlet separator of coal mill and adjust it to the required position.

(2) Check the starting ignition condition of boiler. Make sure that water level of boiler water storage tank is normal. Activate the air pre-heater,induced draft fan and forced draft fan. Furnace purge has already finished. Activate the primary air fan.

(3) Adjust the inlet wind quality of coal mill. Keep the wind speed of outletprimary airpipe around $20 \mathrm{~m} / \mathrm{s}$.

(4) Make sure that the steam pressure is normal. Open the inlet steam valve of mill air heater wider gradually. Put the air heater into use. Maintain the outlet primary wind temperature within the range of $65^{\circ} \mathrm{C} \sim 82^{\circ} \mathrm{C}$.

(5) Adjust the internal secondary air and external secondary air of plasma burner to ignition position.

(6) According to the activating procedure of the plasma ignition device, activate No.1-No.4 plasma generator in order. Adjust the arc power and limit it around 110kW.Control the wall temperature of plasma burner.

(7) Start the coal mill firstly. After the coal mill running steadily,activate the coal feeder. Adjust and increase the coal supply gradually.

(8) Keep observing the combustion status of plasma burner.

(9) Adjust the primary wind speed and secondary small throttle opening size constantly in order to keep it in a reasonable value. Adjust the arc power of plasma devices and got the reasonable steady burning power. For extending the service time of cathodal and avoiding the frequent change of cathode heads, reduce the arc power appropriately when it gets good firing effect.

(10) If the plasma igniter breaks arc in the "plasma model",the alarm light indicator will give sound-light alarm. The operator shall immediately check whether slide plate gates of related burners are interlocking closed or not. The protection device will stop coal mill running at that time. After confirming slide plate gates well closed, if the arc breaks for the exhausted cathode material, change it as soon as possible. Then resume service. 


\section{Commissioning Scheme on Plasma Ignition System During the Starting Procedure of the Whole Set of Boiler}

(1) Check and make sure that the plasma cooling water pump runs well. The pressure and flow are normal. Check and ensure that the cooling fan runs well. The pressure and flow of carrier wind and image cooling wind are normal.

(2) Power on the plasma ignition device.

(3) Check and make sure that the plasma monitoring devices has put into use. The plasma image fire detecting runs well.

(4) Check and make sure that the coal mill atarts in "plasma starting model".

(5) Adjust the inlet wind quantity of coal mill. Keep the wind speed of outlet primary airpipe within the range of $18-20 \mathrm{~m} / \mathrm{s}$.

(6) Set the current of plasma generator within the range of $180 \mathrm{~A} \sim 210 \mathrm{~A}$.

( 7 ) Start plasma generators successively. Adjust the current and gap between cathode and anode in order to make the arc of plasma generator normal.

(8) When the outlet temperature of coal mill achieves near $70^{\circ} \mathrm{C}$, start coal mill and coal feeder. Coal feed quantity is $20-24 \mathrm{t} / \mathrm{h}$.

(9) Check all plasma combustion condition. If necessary, adjust the power of plasma igniter and primary air flow rate of coal mill to ensure normal burning.

(10) After 30mins steady burning, adjust the coal quantity of coal feeder and primary air flow rate of coal mill in accordance with heating and pressure raising curve.

(11) When the outlet primary wind temperature of air pre-heater is $>160{ }^{\circ} \mathrm{C}$, open the bypass gate of air heater. Stop using hot primary air heater of coal mill.

(12) If it does not catch fire after feeding pulverized coal,stop feeding immediately,keep the furnace underpressure and strengthen ventilation. Feed again after finding out reasons and eliminating faults.

(13) At the initial running stage of plasma ignition burner, open the upper secondary air damper appropriately wider in order to control temperature raising. Keep observing flue temperature and prevent overheat of reheater system.

(14) Monitor the wall temperature of all plasma burners all the time. Make sure that it does not exceed $600^{\circ} \mathrm{C}$.

\section{Outage Scheme of Plasma Ignition System}

(1) Inform operators major in steam turbine and electricity and thermotechnical maintenance personnel before stop runnning the plasma. Make sure that they are ready for the contingency.

(2) Stop running the plasmas one by one before the boiler meets the outage conditions.

(3) Ensure there is one layer of front and back wall pulverized burner in operating state before stopping plasma ignition system. The coal feeding quantity cannot be less than $80 \%$. The coal feeding quantity of front and back wall coal mill shall stay the same. The thermal load shall be even and reduce the flue gas temperature. Then stop all plasma gradually.

(4) The boiler burns steadily after plasma outage. Observe the combustion state of boiler. If there are instable burning signs, such as flame fluctuating, flame dimming, big fluctuation of underpressure furnace, feed plasma in time in order to guarantee steady burning.

(5) Check for the outage plasma ignition system is necessary. Keep it in hot stand-by state and ready for operation.

\section{Commissioning and Operation Effect and Suggestion}

According to the commissioning and operation scheme of plasma ignition system, after finishing commissioning subsystems of 600MW plasma ignition system, debug the ignition system and the 
whole unit. During the start-up commissioning process of the whole set of boiler, the burner was just slightly coked. The boiler started up smoothly. The plasma ignition system stopped running smoothly. The plasma could discharge arc successfully and immediately and burn steadily with low load. It is concluded that the commissioning and operation scheme of plasma ignition system is feasible.

However, based on the experience and suggestions drawn form plasma ignition system, we can conclude:

(1) Pay special attention to the wall temperature change of plasma burner during the commissioning process. ${ }^{[9-11]}$ Raise the primary wind speed appropriately and reduce the power of plasma generators. Avoiding overheating is the important means to prevent coking.

(2)Guarantee that high-quality coal is used for plasma ignition, the designed coal or checked coal at least.

(3)When adjusting the current of plasma generator, try to keep stable. Adjust the voltage slightly frequently. ${ }^{[9,11]}$ As a result, it will prevent changing cathode heads frequently and decrease arc breaking.

\section{References}

[1] Huang.Jun. Xie.Jianwen.Comparative Study of Application about Boiler Fuel- saving Ignition Technologies [J].North China Electric Power, 2014(1):36-39.

[2] Yu Pengfeng.Preventing slagging technology practice of plasma ignition burners[J].Hunan Electric Power, 2012(04):45-47.

[3] LIU Qing-xin.Comparison between Plasma Ignition and Micro-oil[J].Guangxi Electric Power, 2008(05):68-70.

[4] FU Long-long.Start-up Debugging and Operation of Plasma ignition[J].Thermal Power Generation, 2008(04):50-51.

[5] WANG Da-wei.Start-up Commissioning and Operation of Plasma Ignition System for[J].Guangdong Electric Power, 2011(01):103-105.

[6] CUI Zhen-dong,YIN Li-bao,WEN Zhi-yong,YU Yue-xi.Application of Plasma Ignition without Oil to Thermal Power Plant[J].Guangdong Electric Power, 2009(06):48-52.

[7] .The use and maintenance manual of Z-200 plasma ignition device[R]. :YANTAI LONGYUAN POWER TECHNOLOGY CO.,LTD, 2003.

[8] .4*1000 MW engineering unit 2 boiler in Huaneng Yuhuan power plant[R]. :XIAN THERMAL POWER RESEARCH INSTITUTE CO.,LTD, 2007.

[9] Shang Yu-qin.Application of Plasma Ignition Technique in Power Station Boiler[J].Boiler Technology , 2007(02):68-72. 